\title{
Determination of Some Yield and Morphological Characteristics of Some Forage Pea (Pisum sativum ssp. arvense L.) Genotypes in Bingol Ecological Conditions
}

\author{
Adil Bakoglu (Corresponding author) \\ Department of Plant and Animal Production, Vocational School of Pazar, \\ Recep Tayyip Erdogan University, Rize, Turkey. \\ E-mail: adil.bakoglu@erdogan.edu.tr \\ Muhammed Ikbal Catal \\ Department of Field Crops, Faculty of Agriculture and Natural Sciences, \\ Recep Tayyip Erdogan University, Rize, Turkey. \\ E-mail: muhammed.catal@erdogan.edu.tr \\ Ayhan Bozkurt \\ Institute of Science, Bingol University, Bingol, Turkey \\ E-mail: ayhan121212@outlook.com
}

\begin{abstract}
In this study carried out in Bingöl University Research and Application area in 2015, 14 different forage pea genotypes were established in a randomized block design with three replications. In this study, some yield and morphological characteristics of forage pea genotypes were investigated. As a result of the research; plant height between $41.40-94.93 \mathrm{~cm}$, hay yield $107.81-184.49 \mathrm{~kg} / \mathrm{da}$, number of pods in the plant 10.33-28.33 pcs/plant, number of seeds in the plant 33.33-116.33 pcs/plant, number of seed in pod 3.28-9.44 pcs/pod, seed weight in plant 3.55-21.31 g/plant, cut weight in plant 9.86-30.91 g/plant, cut yield $151.00-856.33 \mathrm{~kg} / \mathrm{da}$, grain yield $31.33-174.67 \mathrm{~kg} / \mathrm{da}$, thousand grain weight $97.10-149.43 \mathrm{~g}$ and harvest index of $21.61-41.41 \%$ has been changed. According to the results of the study, the highest hay yield was obtained from P $101(184,49 \mathrm{~kg} / \mathrm{da})$, the highest cut and grain yields $(856,33 \mathrm{~kg} / \mathrm{da}-174.67$ $\mathrm{kg} / \mathrm{da}$ ) from Gatem 101 genotype respectively.
\end{abstract}

Keywords: Bingöl, forage pea, yield, morphological characteristics.

DOI: $10.7176 / \mathrm{JSTR} / 5-7-06$

\section{Özet}

2015 yılı Bingöl Üniversitesi Araştırma ve Uygulama arazisinde yürütülen bu araştırmada, 14 farklı yem bezelyesi genotipi Tesadüf Blokları Deneme desenine göre üç tekerrürlü olacak şekilde kurulmuştur. Bu araştırmada, yem bezelyesi genotiplerinin bazı verim ve morfolojik karakterleri incelenmiştir. Araştırma sonucunda; bitki boyu 41.40-94.93 cm, kuru ot verimi $107.81-184.49 \mathrm{~kg} / \mathrm{da}$, bitkide bakla say1s1 10.33 $28.33 \mathrm{adet} / \mathrm{bitki}$, bitkide tohum sayıs $33.33-116.33 \mathrm{adet} / \mathrm{bitki}$, baklada tohum sayıs1 3.28-9.44 adet/bakla, bitkide tohum ağırlığ $3.55-21.31 \mathrm{~g} /$ bitki, bitkide kes ağırlığı 9.86-30.91 g/bitki, kes verimi 151.00$856.33 \mathrm{~kg} / \mathrm{da}$, tane verimi 31.33-174.67 kg/da, bin tane ağırlı̆̆1 97.10-149.43 g ve hasat indeksi \%21.6141.41 arasında değişmiştir. Çalışmanın sonucuna göre en yüksek kuru ot verimi P $101(184,49 \mathrm{~kg} / \mathrm{da})$, en yüksek kes ve tane verimi ise sirasıyla $(856,33 \mathrm{~kg} / \mathrm{da}-174.67 \mathrm{~kg} / \mathrm{da})$ Gatem 101 genotipinden elde edilmiştir.

Anahtar kelimeler: Bingöl, yem bezelyesi, verim, morfolojik karakterler. 


\section{Giriş}

Bezelye bitkisi, Leguminosae famiyası Faboideae alt familyası Fabeae takımı Pisum genusunda yer almakta ve insan ve hayvan beslenmesi bakımından önemli bir yere sahip olmaktadır. Tüm bezelyelerin toplandığı Pisum sativum L. türü, son yıllarda iki alt türe ayrılmaktadır. Bunlar; bahçe veya yemeklik bezelye olarak bilinen yeşil ve kuru taneleri için yetiştirilen beyaz çiçekli ssp.sativum, tane yem ve ot amacıyla yetiştirilen mor çiçekli olarak bilinen yem bezelyesi ssp.arvense şeklindedir. Bazı ülkelerde yem bezelyesi insan beslenmesinde de kullanılmaktadır (Açıgöz 2001).

Tek yıllık bir baklagil bitkisi olan yem bezelyesi bitkisinin otunun ve tanesinin besleme değeri ve lezzeti yüksektir. Tanelerinde yüksek oranda protein bulunmakta ve taneleri kırıldıktan sonra kaba yemlere karıştırılabilmektedir. Uygun dönemde biçildiğinde yem bezelyesinin kuru otunda yaklaşı \% $\%$, tanelerinde de \%20-30 oranında ham protein bulunmaktadır. Yem bezelyesi bitkisinden yem olarak hem yeşil taneleri hem kuru otundan faydalandığımız gibi meralarda da yeşil yem bitkisi ve toprağın azot oranını yükseltme amacıyla yeşil gübre bitkisi olarak da değerlendirilmektedir (Özkaynak 1980; Açıgöz 2001).

Ülkemizde farklı genotipler, lokasyonlar ve uygulamalar ile yapılan yem bezelyesi çalıșmalarında farklı sonuçlar alınmıştır. Bu çalışmaların sonuçlarına baktığımızda; Timurağaoğlu ve Altınok, (2004) bitki boyu uzunluğunu $87-116 \mathrm{~cm}$, kuru ot verimini $404-542 \mathrm{~kg} / \mathrm{da}$ arasında; Albayrak vd., (2005) ortalama kuru ot verimini $319 \mathrm{~kg} / \mathrm{da}$; Tamkoç (2007) bitki boyunu 54.8-70.3 cm, bitkide bakla sayısını 6.8-9.4, baklada tohum sayısını 5.2-6.2 ve tohum verimini 32.7-119.7 kg/da arasında; Sayar vd., (2009) bitki boyunu $39.22-79.33 \mathrm{~cm}$, yeşil ot verimini $1156-1658 \mathrm{~kg} / \mathrm{da}$, kuru ot verimini $279-410 \mathrm{~kg} / \mathrm{da}$, bitkide bakla sayısını 6.49-10.00 bakla/bitki, baklada tohum sayısını 4.07-5.27 tohum/bakla, tohum verimini $115.46-210.46 \mathrm{~kg} / \mathrm{da}$ ve bin tane ağırlı̆̆ını 96.75-248.58 g arasında; Bilgili vd., (2010) tohum verimini 352.4-378.3 kg/da arasında; Gündüz (2013) bitkide bakla sayısını 2.67-39.50 adet, bitki boyunu 20.40$65.60 \mathrm{~cm}$, tane verimini $3.0-93.50 \mathrm{~g} / \mathrm{m}^{2}$, baklada tohum sayısın 1 4.0-6.88 adet, kes verimini $50.0-332.5$ $\mathrm{g} / \mathrm{m}^{2}$ ve hasat indeksini \%1.2-43.06 arasında; Varol (2016) bitki boyunu 34.7-120.7 cm, bitkide bakla sayısını 2.6-13.7 adet, 1000 tane ağıllı̆ııı 60.0-256.7 g, baklada tane sayısını 3.7-7.0 adet, tohum verimini $86.6-466.4 \mathrm{~kg} / \mathrm{da}$ arasında; K1lınç (2017) bitki boyunu $50-145 \mathrm{~cm}$, bitkide bakla sayıs1 7-35 adet/bitki, baklada tane sayıs 3-11 adet/bakla, bin tane ağırlı̆̆ $128.39-243.82 \mathrm{~g}$, dekara tane verimi 92.25-143.45 kg/da, hasat indeksini \%53-73 arasında; Bhuvaneswari et al., (2016) bitkide bakla sayısını 1-6 adet, 100 tohum ağırlı̆ııı 11.07-27.32 g, bitki boyunu 30.4-86.4 $\mathrm{cm}$ arasında ve baklada tohum sayısını 3-6 adet; Karaköy ve ark., (2016) ortalama bitki boyunu $6.7 \mathrm{~cm}$, bitkide bakla sayısı 28.6 adet, baklada tane sayısı 6.8 adet, 100 tane ağırlığını $11.4 \mathrm{~g}$, tane verimini $132.8 \mathrm{~kg} / \mathrm{da}$; Kavut ve Çelen, (2017) bitkide bakla sayısını 8.2-9.2, baklada tane sayısı 4.9-5.7, bin tane ağırlı̆ııı 96.1-153.7 g, tohum verimini 95.6-309.8 kg/da arasında; Çaçan ve ark., (2018) kes verimini $160.3-887.0 \mathrm{~kg} / \mathrm{da}$, bin tane ağırlığını 99.1$150.2 \mathrm{~g}$ arasinda; Kumar Singh et al., (2018) bezelye de bitki boyunu $33.98-160.13 \mathrm{~cm}$, bitkide bakla sayısını 5.82-30.42, baklada tohum sayısını 3.01-6.47, 100 tohum ağırlığını 11.18-31.43 g, bitkide biyolojik verimini $15.39-42.53 \mathrm{~g}$, bitkide tohum verimini 1.16-23.61 g, hasat indeksini \%23.45-60.00 arasında; Lal et al., (2018) bitki boyunu 12.70-139.65 cm, bitkide bakla sayısın 10.885-26.060, baklada tohum sayısı 1.738-8.411, 100 tohum ağırlı̆̆ $10.872-27.432 \mathrm{~g}$, bitki başına biyolojik verimi 15.999$38.913 \mathrm{~g}$, hasat indeksi \%23.039-61.684, bitkide tohum ağırlı̆̆ını 4.801-22.496 g arasında; Prasad et al., (2018) bitki boyunu $39.550-137.68 \mathrm{~cm}$, bitkide bakla sayısını 4.181-12.88, bitkide tohum sayısı 2.0495.16, 100 tohum ağırlı̆̆ 16.620-28.50 g, hasat indeksi \%8.494-15.43 arasında; Ton et al., (2018) ortalama bitki boyunu $81.4 \mathrm{~cm}$, bitkide bakla sayısını 14.7, bitkide tohum sayısı $82.1,100$ tohum ağırlığı $18.4 \mathrm{~g}$, tohum verimi $1176 \mathrm{~kg} / \mathrm{ha}$ ve hasat indeksini \% 35.5 olarak bulunduğu araştırıcılar tarafindan belirtilmiştir.

$\mathrm{Bu}$ çalışmanın amacı, bazı yem bezelyesi genotiplerinin bazı verim ve morfolojik özelliklerini tespit ederek bölgenin hayvancılı̆̆ın gelişmesine katkı sağlamak amacıyla Bingöl ilinin ekolojik koşullarına uygun olan genotiplerin belirlenmesidir.

\section{Materyal ve Metod}

$\mathrm{Bu}$ çalışma, Bingöl Üniversitesi Araştırma ve Uygulama arazisinde yürütülmüş ve 14 farklı yem bezelyesi genotipi kullanılmıştır. Çalışmada kullanılan genotiplerin sağlandığı kuruluşlar Tablo 1'de verilmiştir.

Bingöl ilinin uzun yıllar ve 2015 yılı maksimum, ortalama ve minimum sıcaklık değerleri sırasıyla 18.4$19.8 ; 12.0-13.7 ; 6.4-7.2^{\circ} \mathrm{C}$; toplam yağış miktarı $933.9-801.8 \mathrm{~mm}$ 'dir. 2015 yılı, uzun yıllar ortalamasına göre daha sıcak ve daha az yağışlı geçtiği anlaşılmaktadır (Anonim, 2016).

Toprak analizleri Bingöl Üniversitesi Ziraat Fakültesi Toprak Bilimi ve Bitki Besleme Bölümüne ait toprak analiz laboratuvarında yapılmıştır. Toprak analizi sonuçları; toprak bünyesi tınlı, organik maddesi 
yetersiz $(\% 0.26)$, tuzsuz (\%0.0034), toprak $\mathrm{pH}$ 'sı hafif bazik düzeyde (7.22), kireç ve potasyumu yetersiz (\%0.55-22.52), fosfor içeriği ise yeterli (12.17 kg/da) düzeyde olduğu belirlenmiştir.

Arazi çalışması, 2015 yılında derin sürümün ardından kültivatör ve tapan çekilen arazide yapılmıştır. Çalışma tesadüf blokları deneme desenine göre üç tekerrürlü olacak şekilde kurulmuş̧tur. Her parselde 4 sıra ekim yapılmış ve parsel boyu $5 \mathrm{~m}$, sıra arası mesafe $30 \mathrm{~cm}$ olacak şekilde ayarlanmıştır. Ekimde kullanılan tohumluk miktarı dekara $15 \mathrm{~kg}$ şeklindedir. Yetişme sezonu boyunca yabancı ot mücadelesi el çapasıyla yapılmıştır.

$\mathrm{Bu}$ çalışmada; bitki boyu $(\mathrm{cm})$, kuru ot verimi $(\mathrm{kg} / \mathrm{da})$, bitkide bakla sayısı (adet), bitkide tohum sayısı (adet/bitki), baklada tohum sayısı (adet), bitkide tohum ağırlığı (g/bitki), bitkide kes ağırlı̆g $(\mathrm{g} / \mathrm{bitki}$ ), kes verimi $(\mathrm{kg} / \mathrm{da})$, tane verimi $(\mathrm{kg} / \mathrm{da})$, bin tane ağırlı̆ $1(\mathrm{~g})$ ve hasat indeksi (\%) özellikleri incelenmiştir. İncelenen bu özelliklerden elde edilen veriler, Bozkurt (2018) yüksek lisans tezinden üretilmiştir.

Tablo 1. Araştırmada kullanılan yem bezelyesi genotiplerin temin edildiği kuruluşlar

\begin{tabular}{|l|l|l|}
\hline No & Genotip İsmi & Temin Edildiği Kuruluş \\
\hline 1 & 88 PO 38-4-3-683 & Güneydoğu Anadolu Tarımsal Araştırma Enst. Müd.. \\
\hline 2 & Spring Pea 3638 & Güneydoğu Anadolu Tarımsal Araştırma Enst. Müd. \\
\hline 3 & P57B & Güneydoğu Anadolu Tarımsal Arştırma Enst. Müd.. \\
\hline 4 & P57K & Güneydoğu Anadolu Tarımsal Araştırma Enst. Müd.. \\
\hline 5 & P101 & Güneydoğu Anadolu Tarımsal Araştırma Enst. Müd. \\
\hline 6 & P104 & Güneydoğu Anadolu Tarımsal Araştırma Enst. Müd. \\
\hline 7 & Atos & Güneydoğu Anadolu Tarımsal Araştırma Enst. Müd. \\
\hline 8 & Özkaynak & Güneydoğu Anadolu Tarımsal Araştırma Enst. Müd. \\
\hline 9 & Retna & Güneydoğu Anadolu Tarımsal Araştırma Enst. Müd. \\
\hline 10 & Gatem 101 & Güneydoğu Anadolu Tarımsal Araştırma Enst. Müd. \\
\hline 11 & Spring & Güneydoğu Anadolu Tarımsal Araştırma Enst. Müd.. \\
\hline 12 & Bolero & Güneydoğu Anadolu Tarımsal Araştırma Enst. Müd. \\
\hline 13 & Ürünlü & Bursa Uludağ Üniversitesi Ziraat Fakültesi \\
\hline 14 & Gölyazı & Bursa Uludağ Üniversitesi Ziraat Fakültesi \\
\hline
\end{tabular}

Deneme sonucunda elde edilen veriler üç tekerrürlü tesadüf blokları deneme desenine göre SAS istatistik paket programında istatistiki analiz yapılmıştır. Varyans analizi sonuçlarına göre istatistiki açıdan önemli olan özelliklerin ortalamaları Duncan testi ile gruplandırılmıștır (SAS Analysis Software 1999).

\section{Tartışma ve Sonuç}

Genotiplerin bitki boyu, kuru ot verimi, bitkide bakla sayıs1, bitkide tohum sayıs1 ve bitkide tohum ağırlığı değerleri Tablo 2 'de, bitkide kes ağırlığı, kes verimi, tane verimi, bin tane ağırllğı ve hasat indeksi değerleri Tablo 3'de verilmiştir.

Tablo 2 incelendiğinde bitki boyu, kuru ot verimi bitkide tohum sayısı değerleri istatistiki açıdan çok önemli ( $\mathrm{P} \leq 0.01)$; baklada tohum sayısı ve bitkide tohum ağırlığı değerleri önemli $(\mathrm{P} \leq 0.05)$, bitkide bakla sayısı ise önemsiz bulunmuştur. En düşük ve en yüksek değerler sırasıyla; bitki boyu 41.40 (Atos) $94.93 \mathrm{~cm}$ (Gölyazı); kuru ot verimi 107.81 (Spring) - $184.49 \mathrm{~kg} / \mathrm{da}$ (P101); bitkide bakla sayısı 10.33 (P51) - 28.33 adet/bitki (Gatem 101); bitkide tohum sayıs1 33.33 (P101) - 116.33 adet/bitki (Gatem 101); baklada tohum sayısı 3.28 (P104) - 9.44 adet/bakla (P51); bitkide tohum ağırlığı 3.55 (Spring Pea 3-638) - $21.31 \mathrm{~g} /$ bitki (Gatem 101) arasında değişmiş̧ir. Ortalama değerler ise bitki boyu $62.44 \mathrm{~cm}$, kuru ot verimi $148.07 \mathrm{~kg} / \mathrm{da}$, bitkide bakla sayıs1 15.33 (adet/bitki), bitkide tohum sayıs1 67.64 (adet/bitki), baklada tohum sayısı 4.66 (adet/bitki) ve bitkide tohum ağırlığı 8.81 (g/bitki) bulunmuştur.

Tablo 3'de bakıldığında ise bitkide kes ağıllığı, kes verimi, tane verimi, bin tane ağırlı̆̆ı ve hasat indeksi değerleri istatistiki açıdan çok önemli $(\mathrm{P} \leq 0.01)$ bulunmuştur. En düşük ve en yüksek değerler sırasıyla; bitkide kes ağırlığ 9.86 (Atos) - $30.91 \mathrm{~g} /$ bitki (Gölyazı); kes verimi 151.00 (Bolero) - $856.33 \mathrm{~kg} / \mathrm{da}$ (Gatem 101); tane verimi 31.33 (Bolero) - $174.67 \mathrm{~kg} / \mathrm{da}$ (Gatem 101); bin tane ağırlı̆̆ 97.10 (Spring) $149.43 \mathrm{~g}$ (Atos) ve hasat indeksi \% 21.61 (P51) - 41.41 (Retna) arasında değişmektedir. Ortalama değerler ise bitki kes ağırlığ 16.94 (g/bitki), kes verimi $486.50 \mathrm{~kg} / \mathrm{da}$, tane verimi $77.31 \mathrm{~kg} / \mathrm{da}$, bin tane ağırlı̆̆ $117.54 \mathrm{~g}$ ve hasat indeksi \%27.02 olarak bulunmuştur. 
Tablo 2. Genotiplerin bitki boyu, kuru ot verimi, bitkide bakla sayısı, bitkide tohum sayısı, baklada tohum sayısı ve bitkide tohum ağırlığı değerleri.

\begin{tabular}{|c|c|c|c|c|c|c|c|}
\hline No & Genotip İsmi & BB $(\mathbf{c m})$ & $\begin{array}{c}\text { KOV } \\
\text { (kg/da) }\end{array}$ & $\begin{array}{c}\text { BBS } \\
\text { (adet/bitki) }\end{array}$ & $\begin{array}{c}\text { BTS } \\
\text { (adet/bitki) }\end{array}$ & $\begin{array}{c}\text { BATS } \\
\text { (adet/bak) }\end{array}$ & $\begin{array}{c}\text { BTA } \\
\text { (g/bitki) }\end{array}$ \\
\hline $\mathbf{1}$ & 88 PO 38-4-3-683 & $59.07 \mathrm{~cd}$ & $109.41 \mathrm{~b}$ & 12.67 & $57.33 \mathrm{ab}$ & $4.61 \mathrm{~b}$ & $6.08 \mathrm{~b}$ \\
$\mathbf{2}$ & Spring Pea 3-638 & $43.35 \mathrm{~d}$ & $155.94 \mathrm{ab}$ & 12.33 & $55.33 \mathrm{ab}$ & $4.51 \mathrm{~b}$ & $3.55 \mathrm{~b}$ \\
$\mathbf{3}$ & P57B & $74.33 \mathrm{ab}$ & $124.14 \mathrm{ab}$ & 11.67 & $43.67 \mathrm{~b}$ & $3.92 \mathrm{~b}$ & $4.41 \mathrm{~b}$ \\
$\mathbf{5}$ & P51 & $68.07 \mathrm{bc}$ & $122.07 \mathrm{ab}$ & 10.33 & $82.67 \mathrm{ab}$ & $9.44 \mathrm{a}$ & $10.60 \mathrm{ab}$ \\
$\mathbf{6}$ & P101 & $83.41 \mathrm{ab}$ & $184.49 \mathrm{a}$ & 11.00 & $33.33 \mathrm{~b}$ & $3.53 \mathrm{~b}$ & $4.39 \mathrm{~b}$ \\
$\mathbf{7}$ & P104 & $84.87 \mathrm{ab}$ & $147.60 \mathrm{ab}$ & 12.00 & $39.00 \mathrm{~b}$ & $3.28 \mathrm{~b}$ & $4.20 \mathrm{~b}$ \\
$\mathbf{8}$ & Atos & $41.40 \mathrm{~d}$ & $146.86 \mathrm{ab}$ & 12.33 & $53.67 \mathrm{ab}$ & $4.39 \mathrm{~b}$ & $8.38 \mathrm{ab}$ \\
$\mathbf{9}$ & Özkaynak & $60.13 \mathrm{~cd}$ & $146.99 \mathrm{ab}$ & 16.67 & $70.67 \mathrm{ab}$ & $4.27 \mathrm{~b}$ & $8.24 \mathrm{ab}$ \\
$\mathbf{1 0}$ & Retna & $42.60 \mathrm{~d}$ & $174.35 \mathrm{ab}$ & 22.33 & $101.00 \mathrm{ab}$ & $4.52 \mathrm{~b}$ & $14.17 \mathrm{ab}$ \\
$\mathbf{1 1}$ & Gatem 101 & $70.07 \mathrm{bc}$ & $171.87 \mathrm{ab}$ & 28.33 & $116.33 \mathrm{a}$ & $4.52 \mathrm{~b}$ & $21.31 \mathrm{a}$ \\
$\mathbf{1 2}$ & Spring & $41.47 \mathrm{~d}$ & $107.81 \mathrm{~b}$ & 16.33 & $85.67 \mathrm{ab}$ & $5.29 \mathrm{ab}$ & $10.52 \mathrm{ab}$ \\
\hline $\mathbf{1 4}$ & Bolero & $38.21 \mathrm{~d}$ & $134.54 \mathrm{ab}$ & 17.67 & $87.00 \mathrm{ab}$ & $4.94 \mathrm{ab}$ & $12.78 \mathrm{ab}$ \\
\hline $\mathbf{F}$ & Ürünlü & $72.20 \mathrm{ab}$ & $173.36 \mathrm{ab}$ & 13.00 & $53.00 \mathrm{ab}$ & $4.14 \mathrm{~b}$ & $6.00 \mathrm{~b}$ \\
\hline
\end{tabular}

*: $\mathrm{P}<0.5,{ }^{* *}: \mathrm{P}<0.01$; BB: Bitki Boyu; KOV: Kuru Ot Verimi; BBS: Bitkide Bakla Sayısı; BTS: Bitkide Tohum Sayısı; BATS: Baklada Tohum Sayısı; BTA: Bitkide Tohum Ağırlı̆̆ı

Tablo 3. Genotiplerin bitkide kes ağırlığ

\begin{tabular}{|c|c|c|c|c|c|c|}
\hline No & Genotip İsmi & BKA (g/bitki) & KV (kg/da) & TV (kg/da) & BTA (g) & Hİ (\%) \\
\hline 1 & 88 PO 38-4-3-683 & $10.19 \mathrm{~b}$ & $537.67 \mathrm{de}$ & $94.00 \mathrm{bc}$ & $102.43 \mathrm{de}$ & $27.32 \mathrm{ab}$ \\
\hline 2 & Spring Pea 3-638 & $10.91 b$ & $524.67 \mathrm{e}$ & $74.00 \mathrm{de}$ & $105.70 \mathrm{cde}$ & $28.00 \mathrm{ab}$ \\
\hline 3 & P57B & $11.53 b$ & $460.67 f$ & $53.33 \mathrm{f}$ & $106.07 \mathrm{cde}$ & $22.79 \mathrm{ab}$ \\
\hline 4 & P51 & $25.28 \mathrm{ab}$ & $561.00 \mathrm{de}$ & $83.33 \mathrm{~cd}$ & $117.60 \mathrm{cde}$ & $21.61 b$ \\
\hline 5 & P101 & $17.16 \mathrm{ab}$ & $759.00 \mathrm{~b}$ & $75.33 \mathrm{de}$ & $143.30 \mathrm{ab}$ & $19.86 b$ \\
\hline 6 & P104 & $11.16 \mathrm{~b}$ & $572.67 d$ & 74.00de & $127.63 \mathrm{abc}$ & $23.14 \mathrm{ab}$ \\
\hline 7 & Atos & $9.86 \mathrm{~b}$ & $331.33 \mathrm{~g}$ & 71.00de & $149.43 a$ & $33.49 \mathrm{ab}$ \\
\hline 8 & Özkaynak & $19.66 \mathrm{ab}$ & $518.00 \mathrm{e}$ & $67.67 \mathrm{de}$ & $118.20 \mathrm{cde}$ & $24.46 \mathrm{ab}$ \\
\hline 9 & Retna & $18.60 \mathrm{ab}$ & $341.33 \mathrm{~g}$ & $102.67 \mathrm{~b}$ & $110.43 \mathrm{cde}$ & $41.41 \mathrm{a}$ \\
\hline 10 & Gatem 101 & $22.86 \mathrm{ab}$ & $856.33 a$ & $174.67 \mathrm{a}$ & $127.57 \mathrm{abc}$ & $31.29 \mathrm{ab}$ \\
\hline 11 & Spring & $10.69 b$ & $169.00 \mathrm{~h}$ & $64.00 \mathrm{ef}$ & $97.10 \mathrm{e}$ & $30.25 \mathrm{ab}$ \\
\hline 12 & Bolero & $11.80 \mathrm{~b}$ & $151.00 \mathrm{~h}$ & $31.33 \mathrm{~g}$ & $110.87 \mathrm{cde}$ & $33.56 \mathrm{ab}$ \\
\hline 13 & Ürünlü & $26.61 \mathrm{ab}$ & $639.33 c$ & $50.67 f$ & $107.43 \mathrm{cde}$ & $15.08 \mathrm{~b}$ \\
\hline 14 & Gölyazı & $30.91 \mathrm{a}$ & $729.33 b$ & $64.33 \mathrm{ef}$ & $121.73 \mathrm{bcd}$ & $26.07 \mathrm{ab}$ \\
\hline Ort & & 16.94 & 486.50 & 77.31 & 117.54 & 27.02 \\
\hline $\mathbf{F}$ & & $3,781 * *$ & $8,163 * *$ & $8,982 * *$ & $6,229 * *$ & $3,189 * *$ \\
\hline
\end{tabular}


Araştırmadan elde ettiğimiz sonuçlar ile diğer araştırıcıların (Timurağaoğlu ve Altınok, 2004; Albayrak vd., 2005; Tamkoç, 2007; Sayar vd., 2009; Bilgili vd., 2010; Gündüz, 2013; Varol, 2016; Bhuvaneswari et al., 2016; Karaköy ve ark., 2016; Kavut ve Çelen, 2017; Kılınç, 2017; Çaçan ve ark., 2018; Kumar Singh et al., 2018; Lal et al., 2018; Prasad et al., 2018; Ton et al., 2018) bulgular1 arasında benzerlik ve farklılıklar bulunmaktadır. Bu farklılıklar; bölgelerin farklı ekolojik koşulları, farklı uygulamalar (ekim, sulama, gübreleme, hasat gibi) ve farklı genotiplerin kullanılmasından kaynaklanabileceği belirlenmiştir.

\section{Sonuc}

Bingöl şartlarında toplam 14 genotip üzerinde yapılan bu çalışmada, genotiplerin bitkide bakla sayısı hariç diğer tüm özelliklerin (bitki boyu, kuru ot verimi, bitkide tohum sayısı, baklada tohum sayısı, bitkide tohum ağırlığı, bitkide kes ağırlığı, kes verimi, tane verimi, bin tane ağırlığı ve hasat indeksi) istatistiki açıdan önemli olduğu belirlenmiştir. Bir yıllık yapılan bu çalışmanın sonucuna göre kuru ot verimi bakımından P101, kes ve tane verimi bakımından ise Gatem 101 genotipi Bingöl ekolojik koşullarına uygun olduğu sonucuna varılmıştır. Ancak bölgenin ekolojik şartlarına uygun genotiplerin belirlenmesi için bölgenin farklı lokasyonlarında en az iki yıllık çalışma yapılması önerilmektedir.

\section{Kaynaklar}

Açıkgöz E, Uzun A, Bilgili U Sincik M (2001) Bezelye (Pisum sativum L.) çeşitleri arasında yapılan melezlemelerle geliştirilen hatların verim ve bazı kalite özellikleri, Türkiye 4. Tarla Bitkileri Kongresi s. 73-77.

Albayrak, S., Güler, M. ve Töngel, M.Ö., 2005. Yaygın fiğ (Vicia sativa L.) hatlarının tohum verimi ve verim öğeleri arasındaki ilişkiler, Ondokuz Mayıs Üniversitesi Ziraat Fakültesi Dergisi 20(1): 56-63.

Anonim, 2016. T.C. Meteoroloji Genel Müdürlüğü, Resmi İstatistikler” (İllerimize ait istatistiki veriler).

Bhuvaneswari, S., Susheel K.S., Punitha. P., Shashidhar. K.S., Naveenkumar, K.L. and Narendra, P., 2016. Evaluation of morphological diversity of field pea [Pisum sativum subsp. arvense (L.)] germplasm under sub-tropical climate of Manipur. Legume Research, DOI:10.18805/lr.v0iOF.10756.

Bilgili, U., Uzun, A., Sincik, M., Yavuz, M., Aydınoğlu, B., Çakmakçı, S., Geren, H., Avcıŏlu, R., Nizam, İ., Tekeli, A.S., Gül, İ., Anlarsal, E., Yücel, C., Avc1, M., Acar, Z., Ayan, İ., Üstün, A., and Açıkgöz, E., 2010. Forage yield and lodding traits in peas (Pisum sativum L.) with different leaf types, Turk. J. Fields Crops 15: 50-53.

Bozkurt, A., 2018. Bingöl Ekolojik Koşullarında Bazı Yem Bezelyesi (Pisum arvense L.) Genotiplerinin Verim ve Tarımsal Özeliklerinin Belirlenmesi Üzerinde Bir Araştırma. Bingöl Üniversitesi, Fen Bilimleri Enstitüsü, Yüksek Lisans Tezi, 79 s.

Çaçan, E., Kaplan, M., Kökten, K. and Tutar, H., 2018. Evaluation of Some Forage Pea (Pisum

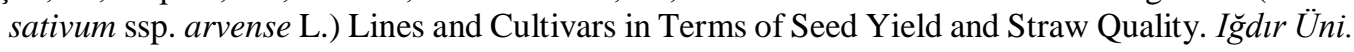
Fen Bilimleri Enst. Der. / Iğdır Univ. J. Inst. Sci. \& Tech. 8(2): 275-284.

Gündüz, H., 2013. Kuzeydoğu Anadolu bölgesi popülâsyonundan seçilen yem bezelyesi hatlarının bazı morfolojik ve tarımsal özellikleri, Atatürk Üniversitesi Fen Bilimleri Enstitüsü Tarla Bitkileri Ana Bilim Dalı, Yüksek Lisans Tezi.

Karaköy, T., Demirbaş, A., Yörük, V., Toklu, F., Baloch, F.S., Ton, A., Anlarsal, A.E. ve Özkan, H., Sivas Ekolojik Koşullarında Soğuğa Dayanıklı Bezelye (Pisum sativum ssp. sativum L. ve ssp. arvense L.) Genotiplerinin Belirlenmesi. Tarla Bitkileri Merkez Araştırma Enstitüsü Dergisi, 25 (Özel say1-1):171-176. 
Kavut, Y.T. ve Çelen, A.E., 2017. Kimi Yembezelyesi Çeşitlerinde (Pisum arvense L.) Sura Arası Mesafelerinin Tohum Verimi ile Bazı Verim Özelliklerine Etkisi Üzerinde Bir Araştırma. Ege Üniv. Ziraat Fak. Derg., 54 (1):79-83.

Kılınç, H.V., 2017. Giresun ilinde yetişen yerel bezelye (Pisum sativum L.) tiplerinin morfolojik karakterizasyonunun belirlenmesi, Ordu Üniversitesi Fen Bilimleri Enstitüsü Tarla Bitkileri Anabilim Dalı Yüksek Lisans Tezi.

Kumar Singh, S., Pratap Singh, V., Srivastava, S., Kumar Singh, A., Kumar Chaubey, B. and Srivastava, R.K., 2018. Estimation of correlation coefficient among yield and attributing traits of field pea (Pisum sativum L.). Legume Research, 41(1) : 20-26.

Lal, K., Kumar, R., Shrivastav, S.P., Kumar, A. And Singh, Y., 2018. Genetic Variability, Character Association and Path Analysis of Seed Yield and Its Contributing Traits in Field pea (Pisum sativum L. var. arvense). Int.J.Curr.Microbiol.App.Sci 7(6): 1815-1820.

Özkaynak İ (1980) Yem bezelyesi (Pisum arvense L.) yerel çeşitler üzerine seleksiyon 1slah çalışmaları, Ankara Üniversitesi Ziraat Fakültesi Yem bitkileri Çayır ve Mera Kürsü̈ü, Ulucan Matbaasi.

Prasad, D., Nath, S., Yadav, K., Kumar Yadav, M. and Kumar Verma, A., 2018. Assessment of genetic variability, correlation and path coefficient for yield and yield contributing traits in field pea (Pisum sativum L. var. arvense). International Journal of Chemical Studies, 6(6): 2330-2333.

Sayar, M.S., Anlarsal, A.E., Açıkgöz, E., Başbağ, M. ve Gül, İ., 2009. Diyarbakır koşullarında bazı yem bezelyesi (Pisum arvense L.) hatlarının verim ve verim unsurlarının belirlenmesi, Türkiye VIII. Tarla Bitkileri Kongresi, Hatay s. 646-650.

Tamkoç, A., 2007. Kışlık olarak ekilen yem bezelyesi hatlarının verim ve bazı bitkisel özellikleri, VII. Türkiye Tarla Bitkileri Kongresi (25-29 Haziran), Çayır Mera ve Yem Bitkileri Bildirileri s. 94-97.

Timurağaoğlu, K.A., Genç, A. ve Altınok, S., 2004. Ankara koşullarında yem bezelyesi hatlarında yem ve tane verimleri, Tartm Bilimleri Dergisi Cilt 10 s. 4.

Ton, A., Karaköy, T., Anlarsal, A.E. and Türkeri, M., 2018. Investigation of grain yield and yield components of some field pea (Pisum sativum L.) genotypes in Mediterranean climate conditions. Legume Research: An International Journal . Feb2018, Vol. 41 Issue 1, p41-47. 7p.

Varol, S., 2016. Sivas ekolojik koşullarında bazı yem bezelyesi genotiplerinin tarımsal özellikleri üzerine bir araştırma, Yüksek Lisans Tezi, Gaziosmanpaşa Üniversitesi Fen Bilimleri Enstitüsü. 